\title{
Megamelus scutellaris (Berg) (Hemiptera: Delphacidae) biology and population dynamics in the highly variable landscape of southern Florida
}

\author{
A.B.C. Goode ${ }^{a, *}$, P.W. Tipping ${ }^{a}$, C.R. Minteer ${ }^{b}$, E.N. Pokorny ${ }^{a}$, B.K. Knowles ${ }^{a}$, J.R. Foley ${ }^{c}$, R. \\ J. Valmonte ${ }^{\mathrm{a}}$ \\ ${ }^{\text {a }}$ USDA-ARS Invasive Plant Research Laboratory (IPRL), 3225 College Ave., Ft. Lauderdale, FL 33314, USA \\ ${ }^{\mathrm{b}}$ University of Florida Indian River Research and Education Center, 2199 S. Rock Rd., Fort Pierce, FL 34945, USA \\ ${ }^{c}$ Department of Entomology, Virginia Polytechnic Institute and State University, 170 Drillfield Drive, Blacksburg, VA 24060, USA
}

\section{H I G H L I G H T S}

- M. scutellaris has established, dispersed, and is impacting control of $P$. crassipes.

- Wild populations of $M$. scutellaris are producing macropters and dispersing via flight.

- Dispersal has been documented from herbicide treated sites and across terrestrial habitat.

- New populations have reached an equilibrium density that does not change with more releases.

\section{A R T I C L E I N F O}

\section{Keywords:}

Pontederia crassipes

Waterhyacinth

Invasive species

Dispersal

Biological control

\begin{abstract}
A B S T R A C T
Changes to the historical flow and nutrient levels of freshwater bodies in Florida have made control of waterhyacinth difficult. Biological control agents were introduced to augment herbicidal control of this plant. The newest insect agent, Megamelus scutellaris, was released in 2010, has established, and has been documented dispersing more than $6 \mathrm{kms}$ away from release locations, across aquatic and terrestrial habitats. These insects were able to successfully disperse away from herbicide treated areas and across terrestrial habitats to reach new mats of waterhyacinth. Macropterous individuals were the first $M$. scutellaris documented at three non-release sites, indicating that the established wild populations are producing flighted individuals and are dispersing actively. Established populations appear to have reached an equilibrium density of $10.74 \pm 19.74 \mathrm{M}$. scutellaris/ $\mathrm{m}^{2}$ and this does not fluctuate with additional releases.
\end{abstract}

\section{Introduction}

The quantity, quality, timing, and distribution of water is tightly controlled across the transformed Everglades landscape in Florida, especially in the region from Lake Okeechobee to the south. The management of this water provides irrigation, flood control, nutrient management, and preserves drinking water for metropolitan areas. Management was accomplished through an extensive system of canals, water control structures, pumps, culverts, and other structures that can move water from Lake Okeechobee to the Atlantic Ocean or Gulf of Mexico. Water can also be moved within the system to agricultural areas and stormwater treatment areas (STAs) to water conservation areas, tribal lands, then to Everglades National Park, and finally Florida Bay (Izuno et al., 1999). Aside from large scale land use changes caused by agriculture and metropolitan development, water management is the primary abiotic restoration issue facing the Everglades (Sklar et al., 2005). Historically, water spilled from the southern edge of Lake Okeechobee and flowed slowly south through the original Everglades with seasonally changing levels and rates (Engstrom et al., 2006). In 1930, the Rivers and Harbors Act authorized the construction of more than $129 \mathrm{kms}$ of dike around Lake Okeechobee, primarily on the southern edge, cutting off the original flow patterns. By the 1960s, this

\footnotetext{
* Corresponding author at: Department of Wildlife Ecology and Conservation, Institute of Food and Agricultural Sciences, University of Florida, 110 Newins-Ziegler Hall, Gainesville, FL 32611, USA.

E-mail addresses: ashleybc@ufl.edu (A.B.C. Goode), Philip.Tipping@usda.gov (P.W. Tipping), c.minteerkillian@ufl.edu (C.R. Minteer), Eileen.Pokorny@usda.gov (E.N. Pokorny), folejr@vt.edu (J.R. Foley).
} 
had expanded to over $225 \mathrm{kms}$ of dikes and levees surrounding the lake (USACE). Now water flows in controlled canals with levels and rates that change frequently causing unseasonably high or low water levels across Lake Okeechobee and other connected bodies of water and resulting in significant modifications to the native ecosystem (Perry, 2008).

Human activities have also transformed the historically low nutrient greater Everglades environment into a more eutrophic system (Engstrom et al., 2006). This has posed a serious obstacle for the restoration of the Everglades and was the impetus for the 1994 Everglades Forever Act (EFA) with the goal of reducing phosphorus in the water to $10 \mathrm{ppm}$ system wide (FDEP). The EFA made it mandatory for agricultural areas to mitigate nutrients being released into the canal systems, it also mandated the creation of STAs to clean the water before it is released south into water conservation areas and then to Everglades National Park (Izuno et al., 1999, Light, 2010).

Artificial water level changes and eutrophic water have exacerbated the challenges posed by invasive aquatic plants (Center and Durden, 1981, Reddy and DeBusk, 1984). One of the most problematic nonnative invasive species is waterhyacinth (Pontederia [Eichhornia] crassipes (Mart.) Solms Commelinales: Pontederiaceae) which was introduced to Florida in the 1880s. Pontederia crassipes spread rapidly through the waterways and by the mid-1900s was a costly problem for shipping and transportation activities (Center, 1994). This species grows quickly in nutrient-rich water creating dense mats that can impede or block boat traffic and obstruct water control structures (Center et al., 2002). It became such a nuisance that the U.S. Army Corps of Engineers was given the permission to control it by any means necessary (Izuno et al., 1999, Rivers and Harbors Appropriation Act of 1899 [33 U.S.C. 403, Chapter 425, March 3, 1899; 30 Stat. 1151]). Effective herbicides approved for aquatic use became available in the 1940s and 1950s and have since been the primary management method for this species (Schmitz et al., 1993, Gettys et al., 2014).

Despite the repeated herbicide treatments that now commonly occur, $P$. crassipes populations rebound quickly and can double in biomass in less than two weeks (Reddy and DeBusk, 1984). In addition to vegetative growth, this species also reproduces from seed, which can remain viable in the hydrosoil for up to twenty years (Matthews et al., 1977). In order to find a more sustainable solution other than the perpetual applications of herbicides, a classical biological control project was started in the 1960s (Center, 1996) resulting in the release of three species of insects, two beetles and one moth, that have established in the U.S. The first biological control agents were two weevils: Neochetina eichhorniae Warner (Coleoptera: Curculionidae) and Neochetina bruchi Hustache (Coleoptera: Curculionidae) which were released in the early 1970s (Perkins, 1973, Center, 1994), followed by a moth, Niphograpta (Sameodes) albiguttalis (Warren) (Lepidoptera: Crambidae), in 1977 (Center and Durden, 1981). Currently, the Neochetina spp. are common everywhere $P$. crassipes is found in Florida while $N$. albiguttalis is found primarily in the edges of expanding mats of $P$. crassipes (Tipping et al., 2014a). After these introductions, research on developing new agents for this weed largely ceased because of a lack of financial resources and the prioritization of new weed species.

Interference from herbicides has prevented the first three agents from achieving their maximum impact on $P$. crassipes because spraying rapidly reduces plant populations over a wide area. Both Neochetina spp. and $N$. albiguttalis have juvenile stages that remain within the petioles and roots of $P$. crassipes which die along with the plants, thereby preventing the buildup of insect densities necessary for suppression (Haag, 1986, Wilson et al., 2006). Despite this interference, these earlier agents do provide significant management benefits by decreasing biomass and seed production while increasing the susceptibility of the plant to herbicides (Tipping et al., 2014a, Tipping et al., 2017). Active integration is possible; Haag (1986), Haag et al. (1988), and Haag and Habeck (1991) modified the patterns and timing of herbicide applications to enhance the herbivory impacts from Neochetina spp. including varying the herbicide spray coverage and treating smaller areas sequentially. These integrated strategies allowed for untreated $P$. crassipes to act as refuges for the insects, thus maintaining their populations at levels that could significantly impact the remaining, untreated plants and impede regrowth.

Research on new biological control agents resumed in 2007 and focused on Megamelus scutellaris (Berg) (Hemiptera: Delphacidae), a delphacid planthopper found in Argentina and Paraguay. All life stages of $M$. scutellaris beyond the egg stage are vagile, allowing them to disperse from herbicide treated areas as plants become unsuitable. Females predominantly oviposit on the isthmus between the petiole and the lamina of $P$. crassipes (Sosa et al., 2005) and eggs can continue to develop even after the plant begins to degrade due to leaf senescence or herbicide mortality (pers. obs.). Following oviposition, nymphs emerge 1-2 weeks later and are mobile enough to move between plants (Sosa et al., 2005) which allows them to abandon sprayed, dying plants and disperse to healthier ones. Megamelus scutellaris is also wing dimorphic whereby adults can be either macropterous (flighted) or brachypterous (non-flighted). However, the overwhelming majority of M. scutellaris that have been produced for field release in Florida were brachypterous (Fitzgerald and Tipping, 2013). Since its release in 2010, M. scutellaris has established persistent populations and dispersed into nearby areas (Tipping et al., 2014b). The objectives of the present study were to monitor the $M$. scutellaris population densities, dispersal rates, and to quantify its impact on $P$. crassipes populations across a highly managed landscape. Secondarily, experimental plots were established to assess the potential for an integrative plant management strategy using herbicides and biological control. (See Table 1)

\section{Methods}

\subsection{Monitoring of release and control sites}

Megamelus scutellaris were mass reared under laboratory conditions at the USDA-ARS Invasive Plant Research Laboratory (IPRL) in Ft. Lauderdale, FL to support the release of almost 3 million insects from 2011 through 2020. Planthoppers were deployed at release sites using both direct releases of adults on plants and by placing egg-laden plants within existing P. crassipes populations (Tipping et al., 2014b, Goode et al., 2019; Fig. 1). Experimental control sites where no releases occurred were located at varying distances from the release sites (indicated by white squares in Fig. 1). During 2017-2020, 12 release sites were established and paired with 12 control sites located 1-2 km from the paired release site. Control sites were monitored regularly for the presence of $M$. scutellaris following their assumed dispersal from release sites. Sites were chosen based on accessibility and plant species present and were monitored from boats or by wading in from the bank. To reduce the movement of the deployed egg-laden $P$. crassipes, sites were chosen with intermingled populations of non-floating plants such as cattail (Typha domingensis Pers.), dollarweed (Hydrocotyle umbellate L.), or alligator flag (Thalia geniculate L.). Two additional release sites without paired control sites were added in 2017. These sites were monitored for population fluctuations of both the M. scutellaris and plant community, persistence during $P$. crassipes control measures (herbicide treatments and water level changes), as well as local dispersal of $M$. scutellaris within existing mats of $P$. crassipes.

Monitoring surveys consisted of either ten samples of five plants, where five individual, adjacent $P$. crassipes plants were visually examined for the presence of $M$. scutellaris or counts were made of numbers in ten bucket samples (Fig. S1). The type of survey conducted was based on the site characteristics at the time of sampling, primarily water level, and they are considered to provide comparable estimates of insect numbers (pers. obs.). Bucket samples were used when water levels were sufficient to submerge the $P$. crassipes plants; if the water was too shallow, individual plants were sampled. Bucket samples were taken using a 24 L plastic bucket $(39 \times 26 \times 26 \mathrm{~cm})$ with the solid bottom removed and replaced with a $2.5 \mathrm{~cm}$ mesh screen $(26 \times 26 \mathrm{~cm})$. The 
Table 1

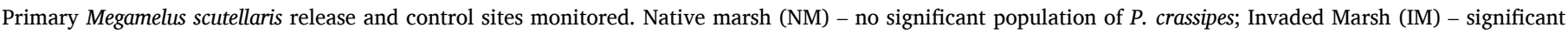

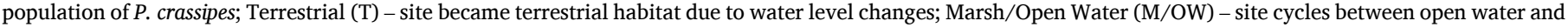

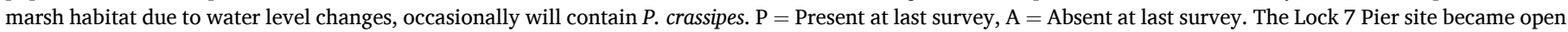

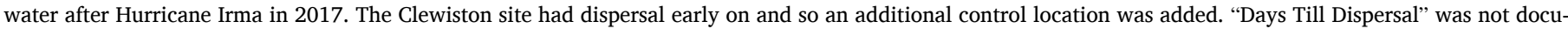
mented for the Lake Okeechobee locations because $P$. crassipes movement is frequent and the sites did not retain persistent populations.

\begin{tabular}{|c|c|c|c|c|c|c|c|c|c|c|c|}
\hline \multirow[t]{2}{*}{ Location } & \multirow{2}{*}{$\begin{array}{l}\text { Site } \\
\#\end{array}$} & \multicolumn{4}{|c|}{ Release Location } & \multicolumn{4}{|c|}{ Control Location } & \multirow[t]{2}{*}{ Distance } & \multirow{2}{*}{$\begin{array}{l}\text { Days Till } \\
\text { Dispersal }\end{array}$} \\
\hline & & Latitude & Longitude & $\begin{array}{l}\text { Final } \\
\text { Habitat }\end{array}$ & M. scutellaris & Latitude & Longitude & $\begin{array}{l}\text { Final } \\
\text { Habitat }\end{array}$ & M. scutellaris & & \\
\hline STA-1E & 1 & 26.6681 & -80.3315 & $\mathrm{IM}$ & A & 26.65953 & -80.31538 & IM & $\mathrm{P}$ & $1.88 \mathrm{~km}$ & 2219 days \\
\hline STA-1W & 2 & 26.6552 & -80.4007 & NM & A & 26.65710 & -80.39629 & OW & A & $0.48 \mathrm{~km}$ & \\
\hline STA-2 & 3 & 26.4144 & -80.5551 & $\mathrm{~T}$ & A & 26.42023 & -80.50010 & IM & $\mathrm{P}$ & $5.52 \mathrm{~km}$ & 58 days \\
\hline STA-3/4 West & 4 & 26.385 & -80.6362 & IM & $\mathrm{P}$ & 26.39244 & -80.63617 & IM & $\mathrm{P}$ & $2.34 \mathrm{~km}$ & 1377 days \\
\hline STA-5 Central & 5 & 26.4615 & -80.9073 & IM & $\mathrm{P}$ & 26.46149 & -80.89889 & NM & A & $0.8 \mathrm{~km}$ & 861 days \\
\hline $\begin{array}{l}\text { Corkscrew Swamp } \\
\text { Sanctuary }\end{array}$ & 6 & 26.4246 & -81.5786 & $\mathrm{IM}$ & $\mathrm{P}$ & 26.42084 & -81.64294 & IM & $\mathrm{P}$ & $6.4 \mathrm{~km}$ & 1013 days \\
\hline Nubbin Slough & 7 & 27.2137 & -80.7234 & $\mathrm{IM}$ & $\mathrm{P}$ & 27.21364 & -80.72559 & $\mathrm{IM}$ & $\mathrm{P}$ & $0.17 \mathrm{~km}$ & 25 days \\
\hline $\begin{array}{c}\text { Lake Okeechobee, } \\
\text { Clewiston Lock }\end{array}$ & 8 & 26.7637 & -80.9169 & NM & A & 26.76355 & -80.89766 & NM & A & $1.91 \mathrm{~km}$ & \\
\hline $\begin{array}{l}\text { Lake Okeechobee, } \\
\text { King's Bay }\end{array}$ & 9 & 27.09290 & -80.8443 & $\mathrm{NM}$ & A & 27.08685 & -80.83228 & $\mathrm{NM}$ & A & $1.26 \mathrm{~km}$ & \\
\hline $\begin{array}{l}\text { Lake Okeechobee, } \\
\text { Torry Island }\end{array}$ & 10 & 26.7328 & -80.70070 & NM & A & 26.71598 & -80.70947 & NM & A & $2.05 \mathrm{~km}$ & \\
\hline $\begin{array}{l}\text { Lake Okeechobee, } \\
\text { Lock } 7 \text { Pier }\end{array}$ & 11 & 26.19560 & -80.829 & M/OW & A & 27.16182 & -80.85490 & NM & A & $4.53 \mathrm{~km}$ & \\
\hline \multirow[t]{2}{*}{$\begin{array}{l}\text { Lake Okeechobee, } \\
\text { Clewiston }\end{array}$} & 12 & 26.7606 & -80.917 & NM & A & 26.81282 & -80.99480 & M/OW & A & $3.2 \mathrm{~km}$ & \\
\hline & & & & & & 26.81742 & -81.02140 & M/OW & A & $6.39 \mathrm{~km}$ & \\
\hline
\end{tabular}

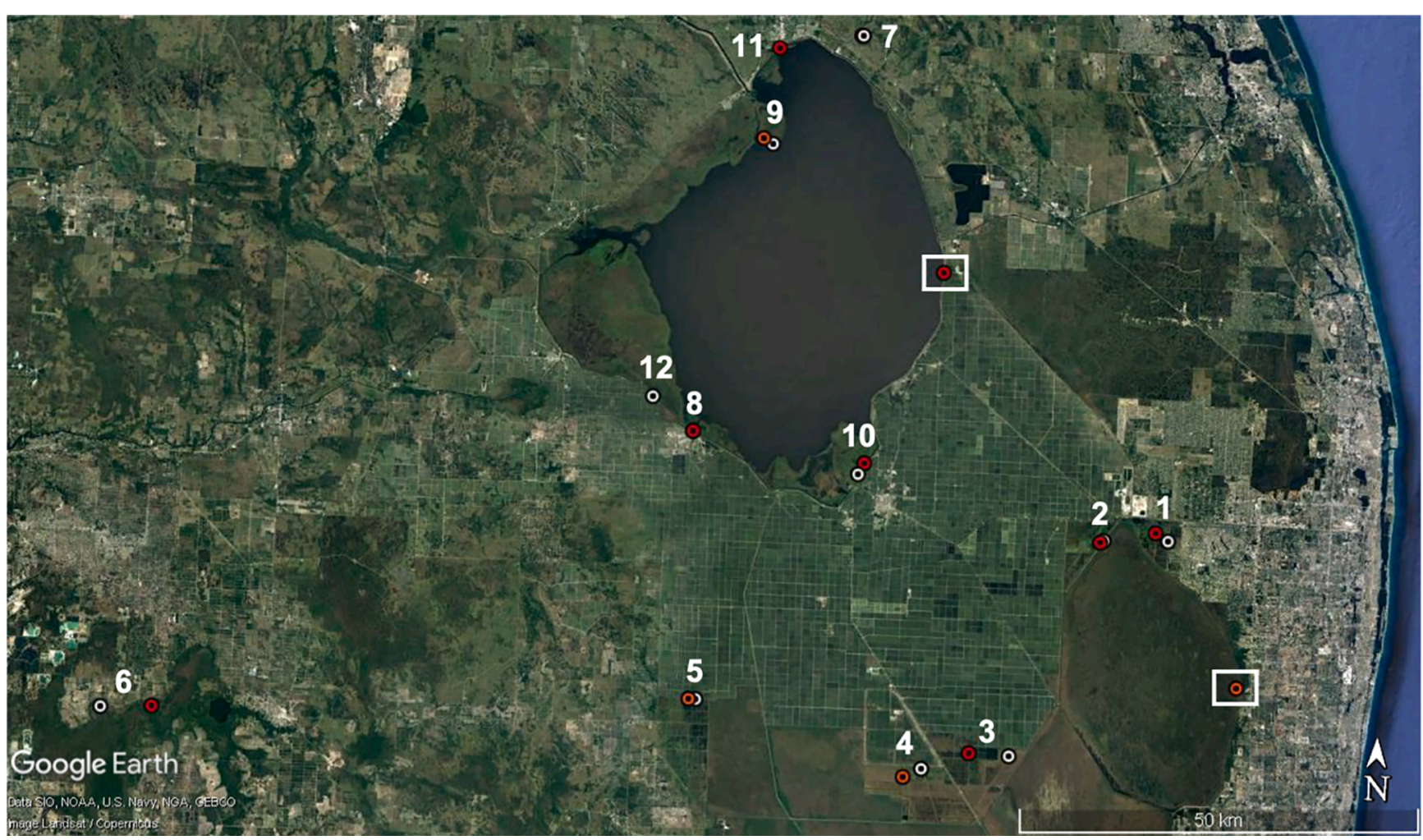

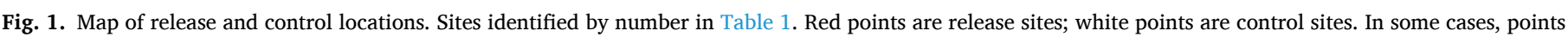

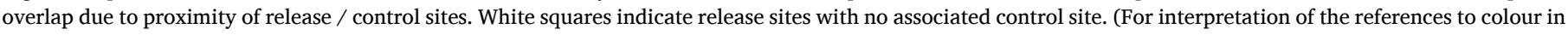
this figure legend, the reader is referred to the web version of this article.)

bucket was then pressed mesh side down onto the plants. The screen submerged a known area of $P$. crassipes $\left(0.07 \mathrm{~m}^{2}, \sim 5\right.$ plants) forcing the insects off the plants and onto the sides of the bucket where they were identified and counted. Individual plants were sampled when water levels were too shallow for bucket samples. When possible, $P$. crassipes were sampled $\sim 2 \mathrm{~m}$ apart. Otherwise, they were sampled evenly across the available $P$. crassipes at the site.

With both of the direct sampling methods described above, the number of brachypterous and macropterous adults and nymphs were recorded as well as site characteristics such as plant community composition and herbicide treatment of $P$. crassipes. If no $M$. scutellaris were found at a site an indirect sampling method was used where 
2-3P. crassipes plants were collected and returned to the lab. Plants were cleaned with insecticidal soap (Safer Insect Killing Soap, Safer Inc., Lititz, PA, USA) at label rate, rinsed with fresh water, placed in $24 \mathrm{~L}$ clear plastic containers with screened lids filled with $4 \mathrm{~L}$ fertilized water (Osmocote Plus 15-9-12 [ICL Fertilizers, Dublin, Ohio; 0.31 g per liter] and chelated iron [Sequestrene $330 \mathrm{Fe}$, BASF Corporation, Research Triangle Park, North Carolina; $0.02 \mathrm{~g}$ per liter]), and maintained under ambient lab humidity and temperature (range: $23-30.5{ }^{\circ} \mathrm{C}$, average: $\left.24.5^{\circ} \mathrm{C}, 12: 12 \mathrm{~L}: \mathrm{D}\right)$. Plants were checked every $2-3$ days for emergence of $M$. scutellaris, which were counted and removed, and sampling ended when no new emergence occurred over two consecutive sample dates. This indirect method was useful in detecting low densities of M. scutellaris or in cases where most of the population existed as eggs. It also detected Kalopolynema ema (Schauff and Grissell) (Hymenoptera: Mymaridae), a parasitoid of $M$. scutellaris (Minteer et al., 2016) which is stenphagous on Megamelus species (Triapitsyn \& Berezovskiy 2002) and whose presence is indicative of a $M$. scutellaris population.

Most of the original releases sites from 2011 to 2017 no longer contained $P$. crassipes by 2017 when the intensive monitoring period began because of water level changes or construction of berms in the areas. Although all 12 release/control site pairs monitored contained populations of $P$. crassipes and M. scutellaris initially, only five sites (Sites $1,4,5,6$, and 7) maintained persistent $P$. crassipes and M. scutellaris populations, while populations of $P$. crassipes in six other sites (Sites 2 , $8,9,10,11$, and 12) disappeared. The last site (Site 3 ) dried out and was replaced by an upland plant community. The areas around the sites were frequently treated with herbicides and water levels were highly variable. These perturbances caused unpredictable and wide fluctuations in the $P$. crassipes populations. Analysis was conducted on data from six of the release/control pairs that were monitored from 2017 to 2020 and the two additional release only sites (indicated by white squares in Fig. 1). The other release/control site pairs (Sites 2, 8, 9, 10, 11, and 12) were not used in the analysis because they transitioned to habitats without $P$. crassipes within the first year of the study.

All statistical tests were conducted in R (version 3.6.1; R Core Team, 2019). The differences in density of $M$. scutellaris between sites was analyzed using generalized linear mixed models fit by the Adaptive Gauss-Hermite Quadrature (glmer function in R, lme4 package, Bates et al., 2015) using the logarithmic link function and location as a random effect. A generalized linear model was built using type of site (release or control), date, number of M. scutellaris released at that specific point on the sampling date ("released"), number of days since the last release event at that specific point ("days since last release"), number of $M$. scutellaris released on the sampling date immediately prior ("released prior"), and the grand total of $M$. scutellaris released at that point as predictive variables ("total released"). Total $M$. scutellaris density was log transformed to fit the model assumptions. The model was then fitted using backwards selection (drop1 function in R, lme4 package, Bates et al., 2015), which removes the variables which contribute the least to the model one at a time, until the lowest AIC is reached. The model was developed using the full complement of release data starting in 2011, then rerun for a subset from 2017 to 2020, during the routine monitoring period. Kruskal-Wallis rank sum tests were used to determine the impact of $P$. crassipes density on the presence of macropterous individuals (using the 2017-2020 dataset only) and to determine differences in $M$. scutellaris density based on site type.

\subsection{Monitoring of refuge areas on Lake Okeechobee}

An assessment of a potential integrated management strategy was conducted by creating insect refuges within treated areas of Lake Okeechobee using floating squares of $0.2 \mathrm{~m}$ diameter PVC pipe $\left(1 \mathrm{~m}^{2}\right.$ in area) that were anchored into persistent mats of $P$. crassipes (Fig. S2). Squares in the north $(\mathrm{N}=4)$ and south $(\mathrm{N}=2)$ ends of Lake Okeechobee were placed in January and February of 2018. Locations were chosen away from popular boat channels to avoid collision risk, reduce the effect of wave action on the squares, and to prevent vandalism. Squares were marked with $1 \mathrm{~m}$ tall PVC posts with flags to identify them to cooperating herbicide treatment crews who were usually able to avoid spraying them. The refuges and the adjacent areas were sampled every 4-6 weeks from February 2018 through February 2019 for densities and biomass of $P$. crassipes, and population densities of Neochetina spp. and M. scutellaris.

Initially, refuge squares contained exclusively $P$. crassipes and were set within larger, contiguous mats consisting primarily of $P$. crassipes. Over the course of the year, the contents of the refuges shifted to a mix of P. crassipes, H. umbrellata, and Polygonum spp. By December 2018, refuges were completely devoid of $P$. crassipes with only a few plants in the adjacent areas. Most sites were treated with herbicide twice during the monitoring period of February - December 2018, although not on the same day for all sites. Different herbicides and concentrations were used depending on the vegetation present including 2,4-D, penoxsulam, and flumioxazin. Although the refuges were generally left untreated, two of the sites and the refuges within were directly affected by an aerial herbicide treatment of flumioxazin in May 2018. Additionally, while all herbicide treatments were applied foliarly, there is the possibility that plants within the refuges were affected systemically, as has been seen in tank experiments (Goode et al. 2019). By February 2019, all sites were dry due to a very low lake stage (less than $4 \mathrm{~m}$ ) and no longer contained any $P$. crassipes in or adjacent to the refuges.

Pontederia crassipes density was measured using a randomly placed $1 / 4$ $\mathrm{m}^{2}$ PVC square and counting the number of plants within and M. scutellaris density was measured using two bucket samples. To determine Neochetina spp. density, five $P$. crassipes plants were collected, weighed, and placed in Berlese funnels for one week to obtain adults and larva. Plant material from the Berlese funnels was then dried to a constant weight to obtain dry weight (DW) biomass for use in statistical analyses and estimation of the final DW biomass within the refuges. After measurements were taken, adult $M$. scutellaris and egg-laden $P$. crassipes plants were released into the refuge (average $=2,355$ M. scutellaris, range $=200-10,763$ insects per release event). Efforts were made to ensure that the number of insects released were approximately equal for each release event across locations.

Data were analyzed using Kruskal-Wallis rank sum tests to look at differences between insect and plant populations inside and outside of the refuges. Additionally, Dunn multiple comparisons using the Benjamini-Hochberg method of $p$-value adjustment for multiple comparisons were used to indicate specific differences between sites. Paired Wilcoxon signed-rank tests were used to compare insect and plant densities within each location.

\section{Results}

\subsection{Monitoring of release and control sites}

Megamelus scutellaris dispersed from release sites and was detected at all control sites with persistent populations of $P$. crassipes. While most release/control site pairs were connected by water, in one instance, M. scutellaris was able to disperse to the control site that was separated from the release site by $\approx 6 \mathrm{kms}$ of terrestrial habitat at the Corkscrew location. The fastest observed dispersal rate was $6.8 \mathrm{~m} \mathrm{day}^{-1}$. Macropterous adults were seen at all sites at least once. At three control sites, indirect sampling of $P$. crassipes detected the insects 29,68 , and 256 days before direct sampling did.

Megamelus scutellaris population densities across all sites and years ranged from $0-458.6 M$. scutellaris $\mathrm{m}^{-2}$ (mean $\pm \mathrm{SE}=23.0 \pm 40.9$ M. scutellaris $\mathrm{m}^{-2}$ ), with release sites routinely containing higher densities $\left(38.1 \pm 51.0\right.$ M. scutellaris $\left.\mathrm{m}^{-2}\right)$ than control sites $(10.7 \pm 19.7$ M. scutellaris $\mathrm{m}^{-2}$; Kruskal-Wallis $\left.\chi^{2}=17.99, \mathrm{df}=1, \mathrm{p} \ll 0.001\right)$. The model describing the population density of $M$. scutellaris was influenced by date, days since last release, number of insects released on the prior sampling date, the grand total released at each point, and site type 
Table 2

Selected model for the density of $M$. scutellaris at field locations 2011-2020 (conditional $\mathrm{R}^{2}=0.81$, marginal $\mathrm{R}^{2}=0.57$ ).

\begin{tabular}{lclrl}
\hline Variable & Estimate & $\mathrm{SE}$ & $\mathrm{z}$ value & $\mathrm{P}$ \\
\hline Intercept & 1.03 & 0.12 & 8.74 & $\ll 0.0001$ \\
Date & -0.0006 & 0.0003 & -2.23 & 0.026 \\
Released & 0.058 & 0.039 & 1.51 & 0.13 \\
Days Since Last Release & -0.076 & 0.028 & -2.76 & 0.0059 \\
Prior & 0.065 & 0.033 & 2.00 & 0.046 \\
Total Released & 0.43 & 0.055 & 7.74 & $\ll 0.0001$ \\
Site - Control & -0.39 & 0.07 & 8.75 & $\ll 0.0001$ \\
\hline
\end{tabular}

(Table 2). Further efforts to refine the model by restricting the model to 2017-2020, when routine monitoring occurred, found that removing the "released" variable improved the model (Table 3 ).

Reductions in $P$. crassipes densities caused by herbicide treatments during 2017-2020 influenced $M$. scutellaris nymph densities (KruskalWallis $\chi^{2}=5.24, \mathrm{df}=1, \mathrm{p}=0.022$ ), with higher nymph densities found where $P$. crassipes density had been reduced $(21.3 \pm 58.6 \mathrm{M}$. scutellaris nymphs $\mathrm{m}^{-2}$ ) compared to where density had not changed $(17.1 \pm 26.4$ M. scutellaris nymphs $\mathrm{m}^{-2}$ ). Reduction of $P$. crassipes density did not significantly influence the presence of macropterous $M$. scutellaris (Kruskal-Wallis $\chi^{2}=3.68, \mathrm{df}=1, \mathrm{p}=0.055$ ), with macropterous individuals occurring in $6.9 \%$ of surveys where $P$. crassipes density was reduced compared to $7.4 \%$ of surveys where $P$. crassipes density was unchanged.

\subsection{Monitoring of refuge areas on Lake Okeechobee}

When the refuges contained plants, $P$. crassipes density was higher inside $\left(44.3 \pm 39.7 P\right.$. crassipes $\left.\mathrm{m}^{-2}\right)$ compared to outside $(35.1 \pm$ 28.7P. crassipes $\mathrm{m}^{-2}$ ) of the refuges (Wilcoxon signed rank test: $\mathrm{V}=$ 264.5, $\mathrm{p}=0.025$ ). Megamelus scutellaris density was also higher inside $\left(318.2 \pm 593.3\right.$ M. scutellaris $\left.\mathrm{m}^{-2}\right)$ compared to outside (15.6 \pm 38.1 M. scutellaris $\mathrm{m}^{-2}$ ) of the refuges (Wilcoxon signed rank test: $\mathrm{V}=199, \mathrm{p}$ $=0.0005)$. Average densities of $M$. scutellaris on Lake Okeechobee at other release locations prior to extirpation of $P$. crassipes were lower still $\left(4.0 \pm 12.0\right.$ M. scutellaris $\left.\mathrm{m}^{-2}\right)$.

Pontederia crassipes densities within the refuges varied by date (Kruskal-Wallis $\chi^{2}=23.12, \mathrm{df}=13, \mathrm{p}=0.04$ ), with highest densities in the spring (March-June) along with $M$. scutellaris densities that peaked in the mid to late spring (April-June) (Kruskal-Wallis $\chi^{2}=26.17, \mathrm{df}=13, \mathrm{p}$ $=0.016$ ). Megamelus scutellaris density per $\mathrm{g}$ DW biomass of $P$. crassipes $\mathrm{g}^{-1}$ varied by date (Kruskal-Wallis $\chi^{2}=28.88, \mathrm{df}=13, \mathrm{p}=0.018$ ), with highest densities in late winter to late spring (February-June).

Neochetina spp. densities (including adults and larva) were similar inside the refuges $\left(179.2 \pm 210.5\right.$ Neochetina spp. $\mathrm{m}^{-2}, 1.1 \pm 2.5 \mathrm{Neo}$ chetina spp. DW biomass of $P$. crassipes $\mathrm{g}^{-1}$ ) and outside of the refuges $\left(184.0 \pm 153.6\right.$ Neochetina spp. $\mathrm{m}^{-2}, 3.7 \pm 7.3$ Neochetina spp. DW biomass of $P$. crassipes $\mathrm{g}^{-1}$ ) and did not vary by date. Neochetina spp. density adjacent to the refuges varied by site (Neochetina spp. $\mathrm{m}^{-2}$ : Kruskal-Wallis $\chi^{2}=14.75, \mathrm{df}=5, \mathrm{p}=0.011$; Neochetina spp. DW biomass of $P$. crassipes $\mathrm{g}^{-1}$ : Kruskal-Wallis $\chi^{2}=15.21, \mathrm{df}=5, p=0.009$ ). The number of Neochetina spp. $\mathrm{m}^{-2}$ varied between sites 1 and $2(\mathrm{Z}=$ 3.30 , $\mathrm{p}$ adj. $=0.014)$ and sites 3 and $2(Z=-2.73$, $\mathrm{p}$ adj. $=0.047)$. When

Table 3

Selected model for total density of M. scutellaris at field locations 2017-2020 (conditional $\mathrm{R}^{2}=0.68$, marginal $\mathrm{R}^{2}=0.60$ ).

\begin{tabular}{lclcc}
\hline Variable & Estimate & SE & z value & P \\
\hline Intercept & 1.14 & 0.067 & 16.93 & $\ll 0.0001$ \\
Date & -0.0006 & 0.0002 & -2.31 & 0.021 \\
Days Since Last Release & -0.14 & 0.027 & -5.08 & $\ll 0.0001$ \\
Prior & -0.054 & 0.028 & -1.94 & 0.053 \\
Total Released & 0.098 & 0.044 & 2.23 & 0.026 \\
Site - Control & -0.49 & 0.057 & -8.63 & $\ll 0.0001$ \\
\hline
\end{tabular}

adjusted for host plant biomass (computed on DW biomass of $P$. crassipes $\left.\mathrm{g}^{-1}\right)$, Neochetina spp. densities also varied between sites, specifically, between sites 1 and $5(Z=-3.01, p$ adj. $=0.039), 2$ and $5(Z=-2.70, p$ adj. $=0.035)$, and 6 and $5(\mathrm{Z}=2.9, \mathrm{p}$ adj. $=0.027)$. Neochetina spp. densities were not affected by $P$. crassipes densities adjacent to the refuges, which varied by site (Kruskal-Wallis $\chi^{2}=11.24$, $\mathrm{df}=5, p=0.047$ ), specifically between sites 1 and $5(\mathrm{Z}=3.07, \mathrm{p}$ adj. $=0.032)$, with all others falling in between. Site 5 initially had a low $P$. crassipes density and, after an aerial treatment of the area on 24 May 2018, P. crassipes never returned to the site but was replaced by Pistia stratiotes L.

\section{Discussion}

Rigorously documenting the population dynamics of $M$. scutellaris on a landscape scale was challenging given the backdrop of intensive and confounding management activities, coupled with the significant environmental variation that occurred during this study. Despite these obstacles, it is clear that the most recent biological control agent released against $P$. crassipes in Florida has both persisted at field locations where $P$. crassipes is found (Tipping et al., 2014b) and has dispersed from those original locations across the landscape. This dispersal predominantly occurred in continuous water bodies with the insects either moving between patches or within continuous mats of $P$. crassipes, or by insects travelling with plants transported by water flow or boat traffic. However, in at least one location, dispersal occurred without any direct water connection between the locations, confirming the ability of $M$. scutellaris to disperse over or through terrestrial habitats.

The dynamic nature of the study sites was evident; many sites changed from invaded marsh habitats that were dominated by $P$. crassipes, to more native marsh communities, with one transforming into an upland plant community because of water level changes. The reasons for the decline of $P$. crassipes at these sites was not determined because of a lack of true insect presence or absence control plots, where insects could have been excluded using insecticide. The frequent herbicide applications would also have made it to difficult to diferentiate the effect of the inscts in the system. However, the decline in densities of $P$. crassipes may have resulted from a combination of the herbivory effects of $M$. scutellaris and Neochetina spp. coupled with an intensive herbicide treatment program. The biocontrol agents have been shown to reduce both the biomass and reproduction in $P$. crassipes, while rendering the weakened plants more susceptible to herbicides (Tipping et al., 2017).

While adults have been documented moving several meters a day (Goode et al., 2019), and have been observed moving 15-20 $\mathrm{m}$ in the weeks following an herbicide application at a site on Lake Okeechobee, nymphs are unlikely to have the ability to move long distances quickly. When plants are treated and begin to degrade, adults tend to disperse to new mats, whereas nymphs tend to migrate to viable (untreated) plants within the same mat, increasing their local density. An indicator of metapopulation dispersal was provided by the refuge monitoring on Lake Okeechobee whereby $M$. scutellaris densities within the refuges were much higher than normally seen across the sites sampled on the lake. The PVC squares successfully contained the P. crassipes, resulting in higher plant density inside the refuges. The square also kept the released egg-laden plants from floating away, likely accounting for the higher density of M. scutellaris, and specifically nymphs. Reduction of local $P$. crassipes populations also affected the presence of macropterous individuals; fewer were detected in mats that had been reduced than those that had not changed. Other delphacid planthopper species have been known to produce more marcopterus individuals at high densities, however in this study the differences were probably due to macropters dispersing away from impacted areas. This is another indicator of functional metapopulation dispersal, as herbicide treatments are constantly occurring across the range of $P$. crassipes in Florida.

The models developed from the release-control site data all indicate that $M$. scutellaris density decreases over the course of the year, and 
while this and other studies (Foley et al., 2016) have shown that adult lifespan and fecundity change with temperature, the decrease seen in this analysis is more likely caused by $P$. crassipes fluctuations. Variation in $P$. crassipes density among refuge sites highlights the differences seen across the landscape where, within a small area, $P$. crassipes presence can vary widely. This variation in space was also seen in the Neochetina spp. density estimates. Neochetina spp. are very sensitive to plant quality. Adults are highly mobile and will disperse to other locations when the quality of the plants declines (Haag, 1986). The estimated Neochetina spp. density from this experiment did correspond with previous estimates for some locations in Florida from Tipping et al. (2014a) and Haag and Habeck (1991). The higher densities within the refuges indicate that these refuges may be useful in helping maintain biological control agent populations in locations where herbicide treatments occur regularly. The higher densities outside the squares at the same sites indicated that it is effective to release $M$. scutellaris at point locations since they will readily disperse throughout the mats.

Macropterous individuals were the first $M$. scutellaris documented at three control sites, and more were detected at control sites overall compared to release sites. This indicated that the established wild populations were producing macropters and dispersing via flight. Dispersal is an inherently risky endeavor as insects are exposed to increased predation and other risks which explains, in part, why densities at control sites were low. Macropterous individuals in other delphacid species are less fecund than brachypterous adults (Denno et al., 1989), so the $F_{1}$ generation at the new location is likely to be small, especially if only one mated female colonizes a new site.

Both the model that included all years (2011-2020) and the one that was limited to the intensively monitored years (2017-2020) had a similar trend of increased density as the total number of $M$. scutellaris released increased. The release strategy for this insect has been to deploy large numbers of adults and egg-infested plants together at a site, which creates waves of propagule pressure, maintaining higher planthopper densities over time and increasing dispersal (Goode et al., 2019). Additionally, the model from 2017 to 2020 did not contain the "released" variable and was significantly impacted by all other variables. When site types are compared, release site densities continue to increase as the total number released increased, whereas control site densities leveled off and were less affected by additional releases. Furthermore, as more $M$. scutellaris are released at a site, more disperse to surrounding areas.

Megamelus scutellaris was chosen as a biological control agent because of its mobility and its suspected ability to survive in a heavily sprayed environment (Sosa et al., 2005). Despite the disorderly nature of the local environments, $M$. scutellaris has established and dispersed. The control sites may provide a useful conservative estimate of the current field densities of $M$. scutellaris in Florida and may provide realistic guidance on the impact of their contribution to the overall biological suppression of $P$. crassipes. Additionally, since $M$. scutellaris has been released in other states (Grodowitz et al., 2014, Moran et al., 2016) and South Africa (Hill and Coetzee, 2017), these densities could be used as a benchmark for other monitoring programs to indicate establishment.

\section{CRediT authorship contribution statement}

A.B.C. Goode: Conceptualization, Methodology, Formal analysis, Investigation, Data curation, Writing - original draft, Writing - review \& editing, Visualization, Supervision. P.W. Tipping: Conceptualization, Methodology, Formal analysis, Investigation, Data curation, Writing review \& editing, Supervision, Funding acquisition. C.R. Minteer: Conceptualization, Methodology, Investigation, Data curation, Writing review \& editing. E.N. Pokorny: Investigation, Writing - review \& editing. B.K. Knowles: Investigation, Writing - review \& editing. J.R. Foley: Conceptualization, Methodology, Investigation, Writing - review \& editing. R.J. Valmonte: Investigation, Writing - review \& editing.

\section{Declaration of Competing Interest}

The authors declare that they have no known competing financial interests or personal relationships that could have appeared to influence the work reported in this paper.

\section{Acknowledgements}

The authors thank Yuichi Shinno, David Prudovsky, Margaret Mcvay, John Laffey, Anthony M. Garcia, Laurent Duverglas, and Luz S. Salinas at the Invasive Plant Research Laboratory for their assistance with Megamelus scutellaris production, colony upkeep, and releases; Susanna Toledo, Mariah McInnis, and Brendon Hession at the Florida Fish and Wildlife Conservation Commission, Jon Lane, David Lattuca, Jessica Fair, and Tyler Green with U.S. Army Corps of Engineers, LeRoy Rodgers, Nathan Ralph, Eric Crawford, Sarah Bornhoeft, Tadese Adeagbo, and Francois Laroche at South Florida Water Management District, and Shawn Clem and Allyson Webb at Corkscrew Swamp Sanctuary for their assistance with access to release and control locations. Mention of trade names or commercial products in this publication is solely for the purpose of providing specific information and does not imply recommendation or endorsement by the U.S. Department of Agriculture (USDA).

\section{Appendix A. Supplementary data}

Supplementary data to this article can be found online at https://doi. org/10.1016/j.biocontrol.2021.104679.

\section{References}

Bates, D., Mächler, M., Bolker, B., Walker, S., 2015. Fitting Linear Mixed-Effects Models Using lme4. J. Stat. Softw. 67 (1), 1-48. https://doi.org/10.18637/jss.v067.i01.

Center, T.D., 1994. Biological control of weeds: waterhyacinth [Eichhornia crassipes] and waterlettuce [Pistia stratiotes]. In: Rosen, D., Bennett, F.D., Capinera, J.L. (Eds.), Pest management in the subtropics: biological control—a Florida perspective. Intercept Ltd., Andover, UK, pp. 481-521.

Center, T.D., 1996. Biological control of water hyacinth in the United States. Strategies for Water Hyacinth Control 1996, 11-14.

Center, T.D., Hill, M.P., Cordo, H., Julien, M.H., 2002. Waterhyacinth. In: Van Driesche, R., Lyon, S., Blossey, B., Hoddle, H., Reardon, R. (Eds.), Biological control of invasive plants in the Eastern United States. USDA Forest Service, Morgantown, West Virginia, pp. 41-64.

Center, T.D., Durden, W.C., 1981. Release and establishment of Sameodes albiguttalis for the biological control of waterhyacinth. Environ. Ent. 10 (1), 75-80. https://doi.org/ 10.1093/ee/10.1.75.

Denno, R.F., Olmstead, K.L., McCloud, E.S., 1989. Reproductive cost of flight capability: a comparison of life history traits in wing dimorphic planthoppers. Ecol. Ent. 14 (1), 31-44. https://doi.org/10.1111/j.1365-2311.1989.tb00751.x.

Engstrom, D.R., Schottler, S.P., Leavitt, P.R., Havens, K.E., 2006. A reevaluation of the cultural eutrophication of Lake Okeechobee using multiproxy sediment records. Ecol. Appl. 16 (3), 1194-1206. https://doi.org/10.1890/1051-0761(2006)016 [1194:AROTCE] 2.0.CO;2.

Fitzgerald, D., Tipping, P.W., 2013. Effect of insect density and host plant quality on wing-form in Megamelus scutellaris (Hemiptera: Delphacidae). Fla. Entomol. 96 (1), 124-130. https://doi.org/10.1653/024.096.0116.

Florida Department of Environmental Protection [FDEP] Lake Okeechobee Watershed. Available online at: https://protectingourwater.org/watersheds/map/lake_okeecho bee. (accessed 5 February 2020).

Foley, J.R., Minteer, C.R., Tipping, P.W., 2016. Differences in seasonal variation between two biotypes of Megamelus scutellaris (Hemiptera: Delphacidae), a biological control agent for Eichhornia crassipes (Pontederiaceae) in Florida. FLA Entomol. 99 (3), 569-571. https://www.jstor.org/stable/24891109.

Gettys, L.A., Haller, W.T., Petty, D., 2014. Biology and control of aquatic plants: A best management practices handbook, third ed. Aquatic Ecosystem Restoration Foundation, Marietta, Georgia.

Goode, A.B.C., Minteer, C.R., Tipping, P.W., Knowles, B.K., Valmonte, R.J., Foley, J.R., Gettys, L.A., 2019. Small-scale dispersal of a biological control agent-Implications for more effective releases. Biol. Control 132, 89-94. https://doi.org/10.1016/j. biocontrol.2019.01.016.

Grodowitz, M. J., Johnson, S., Harms, N. E., 2014. The use of Megamelus scutellaris Berg in the southern U.S. as a biocontrol agent of waterhyacinth (Eichhornia crassipes (Mart)). ERDC/TN APCRP-BC-33. Vicksburg, MS: U.S. Army Engineer Research and Development Center.

Haag, K.H., 1986. Effective control of waterhyacinth using Neochetina and limited herbicide application. J. Aquat. Plant Manage. 24, 70-75. 
Haag, K.H., Habeck, D.H., 1991. Enhanced biological control of waterhyacinth following limited herbicide application. J. Aquat. Plant Manage. 29, 24-48.

Haag, K.H., Glenn, M.S., Jordan, J.C., 1988. Selective patterns of herbicide application for improved biological control of waterhyacinth. J. Aquat. Plant Manage. 26, 17-19.

Hill, M.P., Coetzee, J., 2017. The biological control of aquatic weeds in South Africa: Current status and future challenges. Bothalia 47 (2), 1-12.

Izuno, F.T., Rice, R.W., Capone, L.T., 1999. Best management practices to enable the coexistence of agriculture and the Everglades environment. HortScience 34 (1), 27-33. https://doi.org/10.21273/HORTSCI.34.1.27.

Light, A.R., 2010. Reducing Nutrient Pollution in the Everglades Agricultural Area through best management practices. Nat. Resour. Env. 25, 26-30.

Matthews, L.J., Manson, B.E., Coffey, B.T., 1977. Longevity of water hyacinth (Eichhornia crassipes (Mart.) Solms.) seed in New Zealand. Proceedings 6th AsianPacific Weed Science Society Conference 1968, Vol.1, 263-7.

Minteer, C.R., Tipping, P.W., Knowles, B.K., Valmonte, R.J., Foley, J.R., Gettys, L.A., 2016. Utilization of an introduced weed biological control agent, Megamelus scutellaris (Hemiptera: Delphacidae), by a native parasitoid. Fla. Entomol. 99 (3), 576-578. https://doi.org/10.1653/024.099.0343.

Moran, P.J., Pitcairn, M.J., Villegas, B., 2016. First establishment of the planthopper, Megamelus scutellaris Berg, 1883 (Hemiptera: Delphacidae), released for biological control of water hyacinth in California. Pan-Pac Entomol 92 (1), 32-43. https://doi. org/10.3956/2016-92.1.32.

Perkins, B.D., 1973. Release in the United States of Neochetina eichhorniae Warner, an enemy of waterhyacinth. In: in: Proceedings 26th Annual Meeting South, Weed Sci. Soc. Abstract, p. 368

Perry, W.B., 2008. Everglades restoration and water quality challenges in south Florida. Ecotoxicology 17 (7), 569-578. https://doi.org/10.1007/s10646-008-0240-y.

R Core Team, 2019. R: A language and environment for statistical computing. R Foundation for Statistical Computing, Vienna, Austria https://www.R-project.org/.

Reddy, K.R., DeBusk, W.F., 1984. Growth characteristics of aquatic macrophytes cultured in nutrient-enriched water: I. Water hyacinth, water lettuce, and pennywort. Econ. Bot. 38 (2), 229-239. https://doi.org/10.1007/BF02858838.

Schmitz, D.C., Schardt, J.D., Leslie, A.J., Dray, Jr., F.A., Osborne, J.A., Nelson, B.V., 1993. The ecological impact and management history of three invasive alien aquatic plant species in Florida, in: McKnight, W.N. (Ed.), Biological pollution: the control and impact of invasive exotic species, Indiana Academy of Science, Indianapolis, Indiana, pp. 17-194.

Sklar, F.H., Chimney, M.J., Newman, S., McCormick, P., Gawlik, D., Miao, S., McVoy, C., Said, W., Newman, J., Coronado, C., Crozier, G., Korvela, M., Rutchey, K., 2005. The ecological-societal underpinnings of Everglades restoration. Front. Ecol. Environ. 3 (3), 161-169. https://doi.org/10.1890/1540-9295(2005)003[0161:TEUOER]2.0. CO; 2 .

Sosa, A.J., Lenicov, A.M.D.R., Mariani, R., Cordo, H.A., 2005. Life history of Megamelus scutellaris with description of immature stages (Hemiptera: Delphacidae). Ann. Entomol. Soc. Am. 98 (1), 66-72. https://dpoi.org/10.1603/0013-8746(2005)098 [0066:LHOMSW]2.0.CO;2.

Tipping, P.W., Martin, M.R., Pokorny, E.N., Nimmo, K.R., Fitzgerald, D.L., Dray Jr., F.A., Center, T.D., 2014a. Current levels of suppression of waterhyacinth in Florida USA by classical biological control agents. Biol. Control 71, 65-69. https://doi.org/ 10.1016/j.biocontrol.2014.01.008.

Tipping, P.W., Sosa, A., Pokorny, E.N., Foley, J.R., Schmitz, D.C., Lane, J.S., Rodgers, L., McCloud, L., Livingston-Way, P., Cole, M.S., 2014b. Release and establishment of Megamelus scutellaris (Hemiptera: Delphacidae) on waterhyacinth in Florida. Fla. Entomol. 97, 804-806. https://doi.org/10.1653/024.097.0264.

Tipping, P.W., Gettys, L.A., Minteer, C.R., Foley, J.R., Sardes, S.N., 2017. Herbivory by biological control agents improves herbicidal control of waterhyacinth (Eichhornia crassipes). Invas. Plant Sci. Manage. 10 (3), 271-276. https://doi.org/10.1017/ inp.2017.30.

Triapitsyn, S.V., Berezovskiy, V.V., 2002. Revision of Kalopolynema, with notes on Platypolynema (Hymenoptera: Mymaridae). Fla. Entomol. 85, 611-619. https:// www.jstor.org/stable/3496781.

Wilson, J.R.U., Rees, M., Ajuonu, O., 2006. Population regulation of a classical biological control agent larval density dependence in Neochetina eichhorniae Coleoptera Curculionidae, a biological control agent of water hyacinth Eichhornia crassipes. B Entomol. Res. 96 (2), 145-152. https://doi.org/10.1079/BER2005408.

U.S. Army Corps of Engineers (Jacksonville District) [USACE]. "About Herbert Hoover Dike." https://www.saj.usace.army.mil/HHD/, (accessed 2 September 2020). 